\title{
PELATIHAN PENGOLAHAN DAUN GAHARU MENJADI TEH HERBAL UNTUK ISTRI PETANI ANGGOTA KELOMPOK TANI DESA DUMAN KABUPATEN LOMBOK BARAT
}

\section{Gde Adi Suryawan Wangiyana ${ }^{1)^{*}}$, Dina Soes Putri ${ }^{2)}$, I Gusti Agung Ayu Hari Triandini $^{3)}$}

\footnotetext{
${ }^{1)}$ Fakultas Ilmu Kehutanan,Universitas Nusa Tenggara Barat,email:dede.consultant@ gmail.com

${ }^{2)}$ Fakultas Pertanian, Universitas Muhammadiyah Mataram, email:dina.soes.putri@ gmail.com

${ }^{3)}$ Fakultas Ilmu Kesehatan, Universitas Bhakti Kencana, email:triandinihari@gmail.com
}

\begin{abstract}
ABSTRAK
Pohon gaharu banyak terdapat di sekitar areal pertanian desa Duman dan sebagin besar tidak dimanfaatkan dengan optimal. Padahal bahan tersebut merupakan bahan baku minuman teh herbal yang berkualitas. Pelatihan ini bertujuan untuk memberdayakan istri petani untuk mengolah daun gaharu menjadi minuman teh herbal. Kegiatan ini diharapkan mampu memberikan keterampilan baru bagi istri petani desa Duman sehinnga mampu membantu perekonomian keluarga. Partisipan dalam kegiatan ini sebanyak 20 orang istri anggota kelompok tani Duman. Pengabdian ini dibagi menjadi dua tahap: tahap teori dan tahap praktek. Partisipan diberikan materi terkait bagaimana mengolah daun gaharu menjadi teh herbal pada tahap teori. Praktek langsung dilakukan oleh parisipan berdasarkan teori yang sudah mereka peroleh. Partisipan telah memahami bahwa urutan sistematis pengolahan daun gaharu menjadi teh herbal meliputi: 1) Pemilihan daun, 2) Pengeringan Daun, 3) Pencacahan daun, 4) Oksidasi daun, 5) Penyeduhan daun. Berdasarkan hasil pre-test dan post-test, terjadi peningkatan pemahaman partisipan rata - rata sebesar $70 \%$ mengenai metode pengolahan daun gaharu menjadi teh gaharu secara sitematis. Partisipan memiliki peluang yang bagus untuk mengembangkan produk teh tersebut menjadi industri rumah tangga. Dapat disimpulkan bahwa Istri anggota kelompok tani desa Duman telah memahami cara pengolahan daun gaharu menjadi minuman teh yang berkualitas.
\end{abstract}

Kata kunci: Pengolahan daun, Teh gaharu, Istri petani

\section{ABSTRACT}

Agarwood trees on rice field of Duman Village were not been utilized optimally. On the other hand, this material was a good source of herbal tea. The purpose of this community service is to give training to farmer's wife of Duman Village about how to process agarwood leaves into herbal tea. This community service should give new skill to farmer's wife of Duman village so they could give additional income for their family. Twenty participants of this community service consist of farmer's wife of Duman Village. This community service including two main steps: Theoritical stage and Practical stage. Participant were given theory of processing agarwood leaves into herbal tea in theoretical stage. Participants applied theory that they already got in practical stage. Participant were fully understood about agarwood processing into herbal tea with systematic method. That method including 5 steps: 1) Selecting leaves, 2) Drying leaves, 3) Chopping leaves, 4) Oxidizing leaves, 5) Brewing leaves. There is $70 \%$ average improvement on participants knowledge about processing agarwood leaves into herbal tea based on pre-test and post-test. This herbal tea product has good prospect to be developed into home industry product by participants. It could be concluded farmer's wife of Duman Village were fully understood about agarwood leaves processing method to produce good quality of herbal tea.

Keywords: Leaves processing, Agarwood tea, Farmer's wife 


\section{PENDAHULUAN}

Desa Duman merupakan salah satu desa di Kecamatan Lingsar Kabupaten Lombok Barat Provinsi Nusa Tenggara Barat yang menjadi sentra lahan pertanian, perkebunan dan kehutanan di pulau Lombok [1]. Lahan persawahan di wilyah ini telah menerapkan sistem agroforestri sehingga setiap lahan persawahan umumnya diselingi oleh tanaman pohon baik perkebunan maupun kehutanan. Salah satu tanaman pohon yang banyak terdapat di areal persawahan Desa Duman adalah pohon gaharu (Gyrinops versteegii).

Pohon gaharu tersebut juga banyak terdapat pada areal persawahan yang dikelola oleh Kelompok Tani Duman. Namun karena fokus utama pekerjaan mereka adalah menanam padi dan komoditas pertanian lainnya, komoditas gaharu tersebut sering terabaikan. Akibatnya, kebanyakan pohon gaharu yang ada disana memiliki kondisi fisik yang kerdil dengan diameter batang kurang dari $10 \mathrm{~cm}$. Kondisi ini tidak memungkinkan pohon gaharu tersebut untuk di Induksi agar menghasilkan resin karena batang gaharu yang layak induksi harus memiliki diameter batang lebih dari $10 \mathrm{~cm}$ [8].

Resin gaharu merupakan komoditas gaharu yang sngat diharapkan oleh kelompok tani Desa Duman karena memang memiliki nilai ekonomis tinggi. Akan tetapi dengan kondisi pohon gaharu mereka yang tidak mungkin di Induksi berimplikasi pada tidak akan dihasilkan resin. Selain itu produksi resin sendiri membutuhkan waktu yang relatif lama yaitu lebih dari 10 tahun [3]. Oleh karena itu, perlu dicari pemanfaatan lain dari komoditi gaharu di lahan mereka. Salah satunya adalah untuk dijadikan minuman teh herbal [9].

Teh herbal gaharu menggunakan daun sebagai bahan baku utama. Oleh karena itu , kondisi batang yang kerdil tidak akan menjadi permasalahan yang signifikan. Hal tersebut justru menjadi keuntungan tersendiri karena dengan batang yang kerdil, justru akan memudahkan untuk memetik daun. Sebagai tambahan, dengan memanfaatkan bagian daun, tidak perlu dilakukan penebangan terhadap pohon gaharu seperti halnya jika memanfaatkan resin pada batang.

Kegiatan mengolah daun gaharu menjadi teh herbal cocok dilakukan oleh para istri anggota Kelompok Tani Duman. Hal ini karena mereka mempunyai cukup banyak waktu luang ketika ditinggal oleh suami mereka menggarap sawah. Suami mereka kebanyakan terlalu sibuk mengurus lahan pertanian setiap hari sehingga tidak memungkinkan mereka untuk mengembangkan komoditi lain. Selain itu, pekerjaan mengolah daun gaharu menjadi teh herbal bukan tergolong pekerjaan berat yang membutuhkan banyak tenaga sehingga lebih cocok untuk dikerjakan oleh wanita dibandingkan pria. 
Produk teh herbal yang dihasilkan oleh para istri Kelompok Tani Duman diharapkan mampu memberikan pemasukan tambahan bagi mereka. Hal ini memberikan peluang bagi mereka untuk membantu suami menafkahi keluarga. Oleh karena itulah tujuan dari kegiatan pengabdian kepada masyarakat ini adalah untuk melakukan pelatihan pengolahan daun gaharu menjadi minuman teh herbal kepada para istri anggota Kelompok Tani Duman .

\section{METODE PELAKSANAAN KEGIATAN}

Kegiatan pengabdian kepada masyarakat ini dilakukan ditempat pertemuan kelompok tani Desa Duman, Kecamatan Lingsar, Kabuptan Lombok Barat pada bulan Juni 2019. Metode yang digunakan adalah metode ceramah dan praktik secara langsung. Oleh karena itu kegiatan pengabdian ini dibagi menjadi dua tahap utama yaitu: tahap teori dan tahap praktek [4]. Sebanyak 20 responden yang terlibat dalam kegiatan ini adalah istri petani anggota Kelompok Tani Duman yang memiliki pohon gaharu di lahan pertanian mereka. Survei lokasi pada pohon gaharu partisipan dilakukan terlebih dahulu sebelum masuk tahap teori dan praktek. Dengan demikian tim pengabdian bisa menggambarkan secara detail bagaimana kondisi pohon gaharu mitra pada saat memberikan materi pelatihan.

Pada tahap teori, partisipan diberikan pembekalan materi terkait pengolahan daun gaharu menjadi teh gaharu. Dalam pemaparan teori ditekankan pada 3 hal pokok. Yang pertama adalah bagaimana memilih daun gaharu yang baik untuk dijadikan sampel. Yang kedua adalah bagaimana mengolah daun gaharu tersebut menjadi bahan baku teh herbal yang berkualitas. Ketiga adalah bagaimana melakukan penyeduhan bahan baku teh herbal tersebut untuk menghasilkan minuman teh herbal yang juga berkualitas. Pada tahap teori ini, partisipan diberikan Pre-test dan Post-Test untuk menguji pemahaman partisipan terhadap materi yang diberikan.

Tahap praktik merupakan tahap partisipan mendapat kesempatan untuk mengaplikasikan teori yang telah mereka terima sebelumnya. Pada tahap praktik ini, partisipan secara langsung mengolah daun gaharu menjadi minuman teh herbal dengan didampingi oleh tim pengabdian yang terdiri dari: ahli gaharu dari Fakultas Ilmu Kehutanan Universitas Nusa Tenggara Barat, Ahli Kimia dari Fakultas Pertanian Universitas Muhammadiyah Mataram dan Ahli Pemberdayaan Perempuan dari Fakultas Ilmu Kesehatan Universitas Bhakti Kencana. Pada tahap ini juga dilakukan monitoring dan evaluasi secara langsung hasil produk teh gaharu yang dibuat oleh partisipan. Hal ini dijadikan sebagai dasar untuk menilai kelayakan produk ini untuk dikembangkan menjadi produk Home Industry. Yang berpotensi memberikan pemasukan tambahan untuk partisipan. 


\section{HASIL DAN PEMBAHASAN}

\section{Tahap Teori}

Seperti telah dijelaskan dalam metode, pada tahap ini partisipan diberikan teori mengenai cara mengolah daun gaharu menjadi minuman teh herbal. Antusiasme partisipan dalam menjalani pembekalan materi sangat tinggi. Terbukti dari kehadiran seluruh partisipan dan juga antusiasme mereka untuk mengajukan pertanyaan terkait materi yang diberikan.
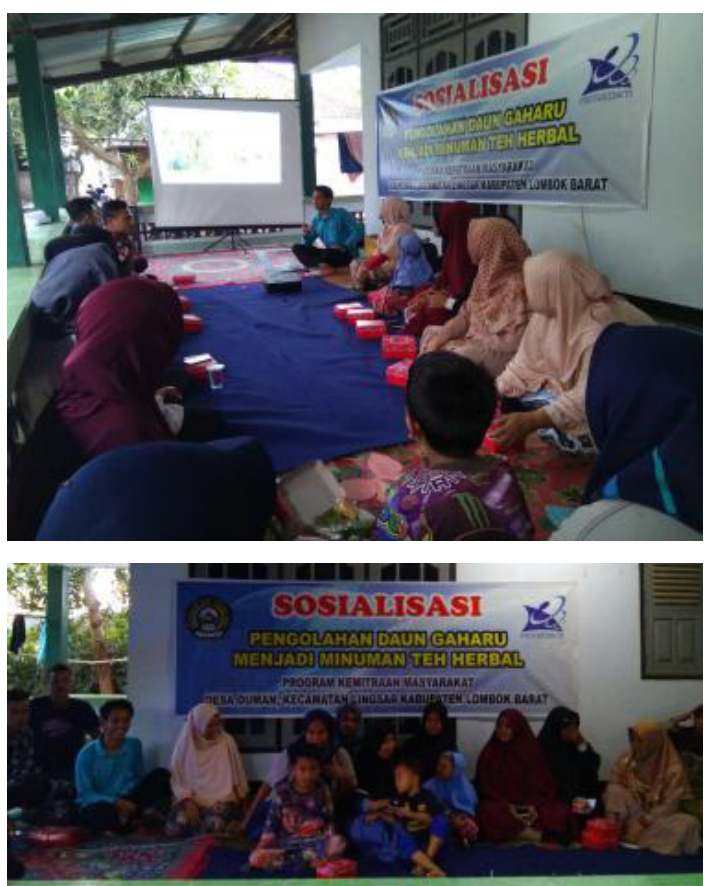

Gambar 1. Sosialisasi dan Pembekalan Materi Pengolahan Daun Gaharu Menjadi Minuman Teh Herbal

Antusiasme yang tinggi tersebut disebabkan karena teh gaharu merupakan suatu inovasi baru bagi partisipan. Selama mereka menanggap bahwa pohon gaharu hanya dapat diambil resin pada bagian batangnya. Resin tersebut dikenal dengan istilah gubal gaharu. Berdasarkan pengalaman mereka, pembentukan gubal pada pohon gaharu membutuhkan waktu yang sangat lama dengan tingkat keberhasilan yang rendah. Dengan demikian mereka menganggap penggunaan daun gaharu untuk dijadikan minuman teh herbal merupakan suatu hal yang menjanjikan untuk dikembangkan.

Tabel 1. Hasil Penilaian Pre-test dan Post-test pada tahap pembekalan teori

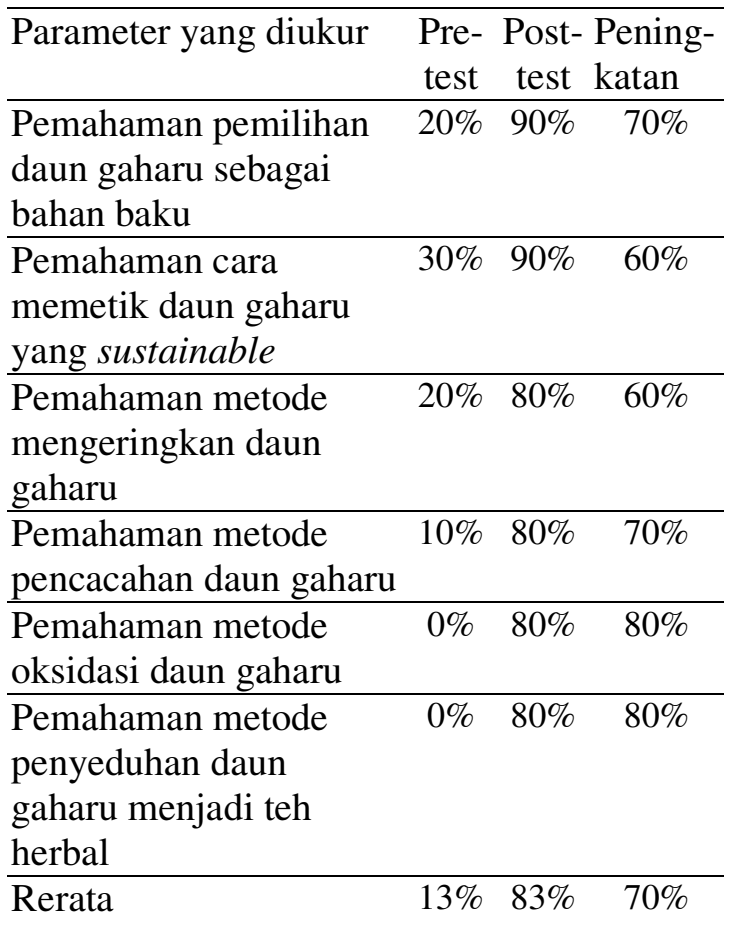

Berdasarkan Hasil Pre-test dan Post-test yang dilakukan terhadap partisipan dalam kegiatan pembekalan, terdapat peningkatan pemahaman yang signifikan. Sebelum mengikuti pembekalan materi, partisipan rata - rata memiliki persentase pemahaman mengenai metode pengolahan daun gaharu menjadi teh herbal sebesar $13 \%$. Setelah mengikuti pembekalan materi, persentase tingkat pemahaman mereka naik menjdi rata - rata sebesar $83 \%$. Hal ini mengindikasikan bahwa terdapat peningkatan pemahaman 
partisipan rata - rata sebesar 70\% (Tabel 1).

Peningkatan tingkat pemahaman ini mengindikasikan bahwa partisipan telah siap untuk mengaplikasikan secara langsung teori yang telah mereka terima. Pemahaman teori ini menjadi penting jika kedepannya partisipan akan mengembangkan produk teh herbal gaharu ini secara mandiri. Dengan dasar teori yang kuat, mereka akan lebih lancar dalam praktek ataupun mengembangkan produk teh gaharu dikemudian hari.

\section{Tahap Praktek}

Tahap praktek dilakukan menggunakan metode Wangiyana dan Sami'un (2018b) dengan beberapa modifikasi. Rancangan tersebut dibuat dalam bentuk SOP baku (Tabel 1). Hal ini bertujuan untuk memudahkan partisipan untuk melakukan praktek secara mandiri.

Tabel 2. Ringkasan SOP Pengolahan Daun Gaharu Menjadi Teh Herbal

\begin{tabular}{ll}
\hline SOP 1 & $\begin{array}{l}\text { Pemilihan Daun } \\
\text { Gaharu }\end{array}$ \\
& $\begin{array}{l}\text { Daun yang dipilih } \\
\text { adalah daun yang } \\
\text { sehat, tidak } \\
\text { mengalami klorosis } \\
\text { (kekuningan), } \\
\text { ataupun nekrosis } \\
\text { (coklat - hitam) serta } \\
\text { tidak terserang hama } \\
\text { dan penyakit } \\
\text { Sebanyak 3 dahan }\end{array}$ \\
\end{tabular}

teratas dari tiap

pohon dipotong,

kemudian daun pada

tiap dahan dipetik

dengan tangan.

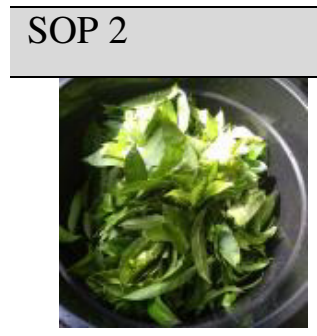

Pencucian Daun

Daun dicuci dalam

wadah ember bersih

dengan

menggunakan air mengalir. Pencucian dilakukan minimal sebanyak 2 kali untuk menjamin daun benar - benar sudah bersih.

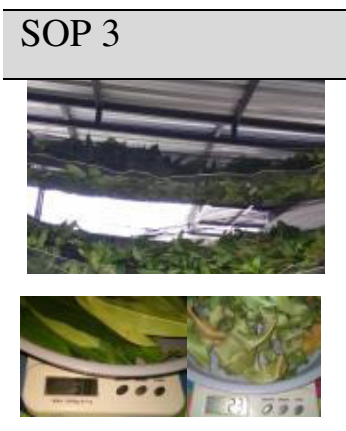

Pengerngan daun

Daun dikering anginkan selama 3 hari pada suhu ruang. Pengeringan dapat menggunakan jaring atau kawat kasa. Pengeringan ideal jika bobot daun telah berkurang $70 \%$ dari semula

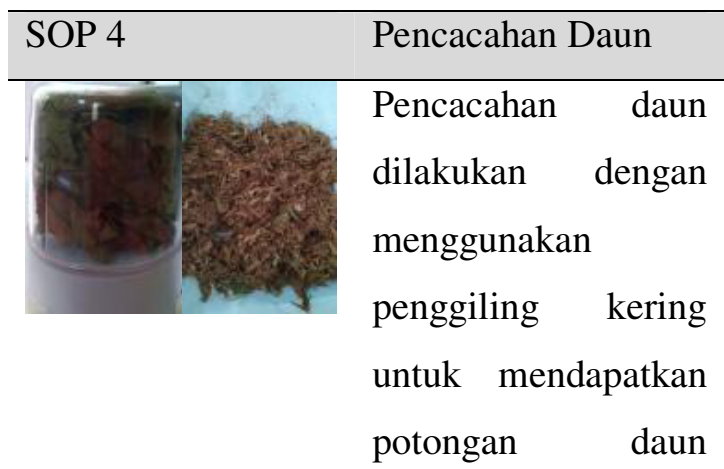




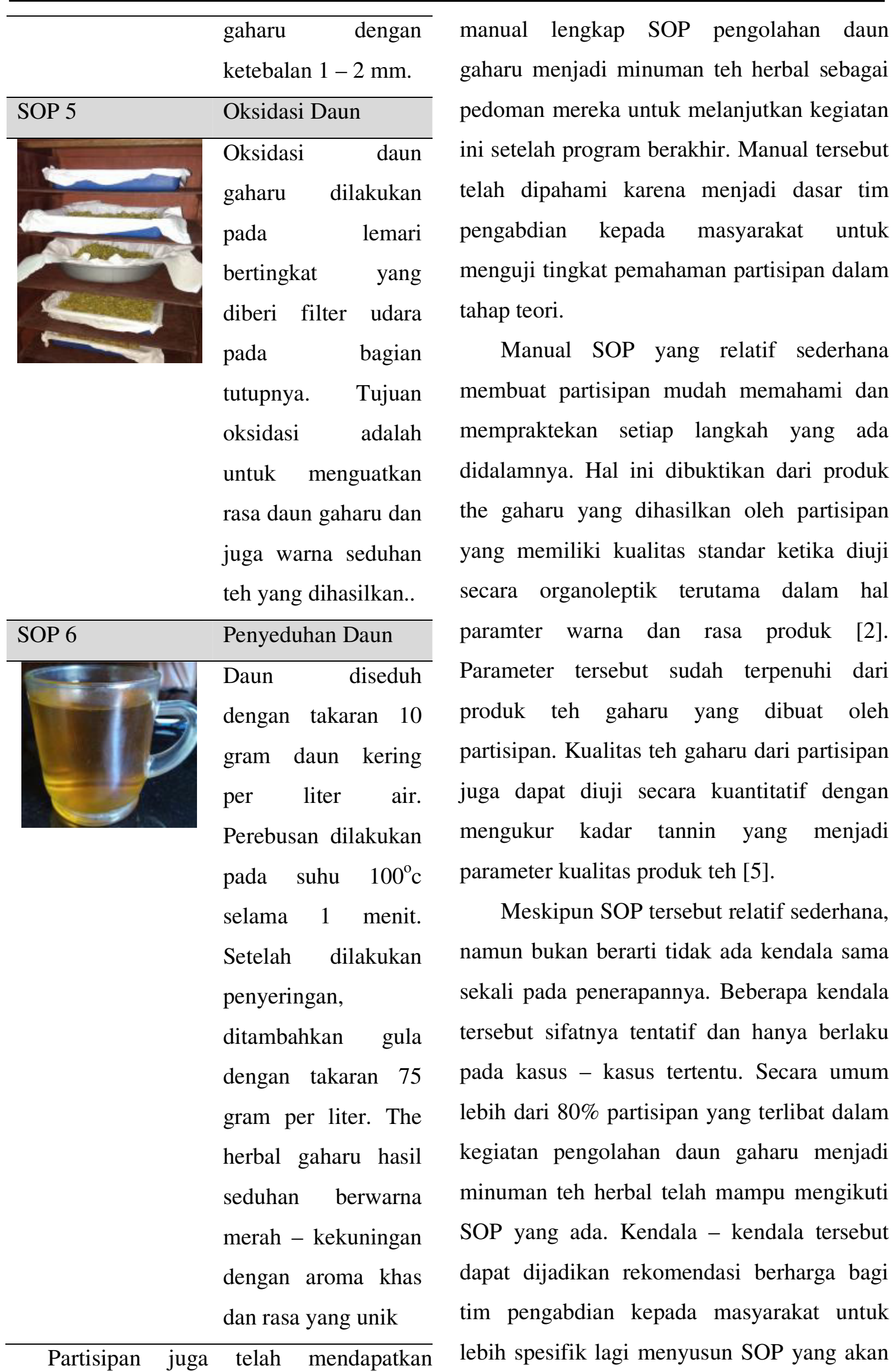


digunakan oleh mitra.

Tabel 3. Kendala dalam penerapan SOP oleh Partisipan Selama Tahap Praktik

\begin{tabular}{ll}
\hline SOP & Kendala \\
\hline SOP 1 & Partisipan kesulitan mengambil \\
& 3 daun teratas jika pohon gaharu \\
& terlalu tinggi \\
\hline SOP 2 & Tidak ada kendala \\
\hline SOP 3 & Partisipan \\
& mengeringkan daun jika kondisi \\
& cuaca mendung atau hujan \\
\hline SOP 4 & Alat pencacah seringkali panas \\
& jika digunakan dalam waktu \\
& terlalu lama \\
\hline SOP 5 & Tidak ada kendala \\
\hline SOP 6 & Partisipan belum terbiasa \\
& menimbang dengan neraca \\
& analitik dengan tingkat presisi \\
& tinggi
\end{tabular}

Terdapat solusi yang berbeda untuk setiap kendala dalam SOP tersebut. Untuk SOP 1 dapat diatasi dengan memberikan tangga serbaguna bagi partisipan. Hal ini dapat memudahkan mereka untuk menjangkau dahan teratas dari pohon gaharu yang tinggi. Untuk SOP 3, pada proses pengeringan dapat menggunakan bantuan kipas angin. Dengan kipas angin pengeringan daun dapat lebih efektif meskipun kondisi cuaca sedang mendung, bahkan hujan. Untuk SOP 6, partisipan diberikan pelatihan sebanyak - banyaknya untuk menimbang menggunakan neraca analitik berulang kali. Dengan demikian, partisipan akan terbiasa menimbang bahan dengan menggunakan neraca analitik. Selain itu tingkat akurasi dari partisipan juga akan meningkat jika telah terbiasa menggunakan neraca analitik.

Produk teh gaharu memiliki prospek yang bagus untuk dikembangkan di pulau Lombok. Secara umum, teh gaharu sebenarnya telah dikenal secara regional terutama diwilayah Pulau Sumatera. Teh gaharu tersebut dikenal dengan nama teh Aqila dan memiliki prospek yang bagus untuk dikembangkan berdasarkan analisis kelayakan finansial [6]. Untuk wilayah Pulau Lombok, teh gaharu yang dihasilkan bukan berasal dari genus Aquilaria (seperti halnya teh Aqila), melainkan dari spesies Gyrinops versteegii. Oleh karena itulah, teh gaharu ini memiliki peluang bagus untuk bersaing di pasar nasional. Selain itu, teh gaharu yang diproduksi oleh partisipan memiliki kualitas standar sesuai dengan kriteria warna dan rasa menurut [2]. Oleh karena itulah, kedepnanya partisipan diharapkan mengembangkan produk ini sebagai salah satu upaya untuk menambah pemasukkan keluarga.

\section{KESIMPULAN}

Dapat disimpulkan bahwa istri petani Kelompok Tani Duman sebagai partisipan dalam kegiatan pengabdian kepada masyarakat ini telah memahami dan mampu mengolah daun gaharu menjadi minuman teh herbal dengan menggunakan metode sistematis sesuai SOP baku yang telah 
ditetapkan sehingga mampu menjaga

kualitas produk yang mereka hasilkan

\section{SARAN}

Sebaiknya dilakukan uji fitokimia berupa perhitungan kadar tannin jika produk teh gaharu dari partisipan akan dikembangkan untuk produk komersial. Kadar tannin tersebut dapat sekaligus dijadikan perbandingan kuantitatif terhadap teh herbal gaharu dan teh herbal lainnya yang beredar di pasaran.

\section{UCAPAN TERIMAKASIH}

Terima kasih diucapkan kepada Kemenristekdikti atas pendanaan skema Program Kemitraan Masyarakat yang menjadi bahan utama penulisan artikel ini. Terima kasih pula diucapkan untuk LLDIKTI wilayah VIII yang telah memfasilitasi Tim Pengabdian Kepada Masyarakat dalam melakukan Program Kemitraan Masyarakat Sehingga dapat terlaksana dengan baik.

\section{DAFTAR PUSTAKA}

[1] Anonim, 2018. Provinsi Nusa Tenggara Barat Dalam Angka 2018. Badan Pusat Statistik Provinsi Nusa Tenggara Barat. Mataram, Indonesia.

[2] Wangiyana, I G. A. S. dan Sami'un. 2019. Pengolahan Daun Gaharu (Gyrinops Versteegii) Menjadi Teh Herbal Dengan Kualitas Warna dan Rasa yang Disukai. Prosiding Seminar Nasional SAINSTEK 2018. Oktober 2018. Mataram, Indonesia. Hal. 156 162.
[3] Akter, S., Islam, M.D. Zulkefeli, M., Khan, S. I. 2013. Agarwood Production a Multidiciplinary Field to be Explored in Bangladesh. International Journal of Pharmaceutical and life science. 2 (1): $22-32$.

[4] Cooks, L. and Scharrer, E. 2006.

Assessing Learning in Community Service Learning: A Social Approach. Michigan Journal of Community Service Learning. (2006): 44 - 55.

[5] Kasnabis, J., Rai, C., Roy, A. 2015. Determination of Tannin Content by Titrimetric Method from Different Types of Tea. Journal of Chemical and Pharmaceutical Research. 7 (6): 238 241.

[6] Karsianingsih, E. 2016. Analisis

Kelayakan Finansial dan Strategi Pengembangan The Gaharu di Kabupaten Bangka Tengah (Studi Kasus: Teh Gaharu "Aqilla” Gapoktan Alam Jaya Lestari. Jurnal AGRARIS. (2) 2: $143-151$

[7] Wangiyana, I G. A. S. dan Sami'un, 2018. Characteristic of Agarwood Tea from Gyrinops versteegii Fresh and Dry Leaves. Jurnal Sangkareang Mataram. 4 (2): 41 - 44.

[8] Wangiyana, I G. A. S., Wanitaningsih, S. K., Sanjaya, A. 2018a. Bioinduksi Gyrinops versteegii Menggunakan inokulan Berbahan Baku Medium Tauge dengan Berbagai Kedalaman Pengeboran. Prosiding Seminar Nasional Pertanian 2018. Januari 2018. Mataram, Indonesia. Hal. 144 - 152.

[9] Wangiyana, I G. A. S., Triandini, I G. A. A. H., Putradi, D., Wangiyana, W., 2018b. Tannin Concentration of Gyrinops Tea from Leaves of Juvenile and Mature Agarwood Trees (Gyrinops versteegii Gilg (Domke)) with Different Processing Methods. Journal of Chemical and Pharmaceutical Research. 10 (10): $113-119$. 